\title{
Review and Updates in Regenerative and Personalized Medicine, Preclinical Animal Models, and Clinical Care in Cardiovascular Medicine
}

Emanuele Barbato, ${ }^{1,2}$ Paul J. Barton, ${ }^{3}$ Jozef Bartunek, ${ }^{1}$ SallyHuber, ${ }^{4}$ Borja Ibanez ${ }^{5,10}$

Daniel P. Judge, ${ }^{6}$ Enrique Lara-Pezzi, ${ }^{5}$ Craig M. Stolen ${ }^{7} \&$ Angela Taylor, ${ }^{8}$

Jennifer L. Hall. ${ }^{9}$

1 Cardiovascular Center, Aalst OLV Clinic, Aalst, Belgium

2 Belgium and Department of Advance Biomedical Sciences, University of Naples, Federico II, Italy

3 National Institute of Heart Research, Royal Brompton, Cardiovascular Biomedical Research Unit, Royal Brompton Hospital, London, UK

4 Department of Pathology, University of Vermont, Colchester, VT, USA

5 Centro Nacional de Investigaciones Cardiovasculares Carlos III, Madrid, Spain

6 Johns Hopkins Center for Inherited Disease, Baltimore, MD, USA

7 Boston Scientific Corporation, St. Paul, MN, USA

8 Cardiovascular Research Center, Department of Medicine, University of Virginia, Charlottesville, VA, USA

9 Lillehei Heart Institute, Department of Medicine, University of Minnesota, 4-138 Cancer and Cardiovascular

Research Building 2231 6th Street SE, Minneapolis, MN 55455, USA

10 IIS-Fundación Jiménez Díaz Hospital, Madrid, Spain

\section{Corresponding author:}

Jennifer Hall,

Lillehei Heart Institute,

Department of Medicine,

University of Minnesota,

4-138 Cancer and Cardiovascular Research Building 2231 6th Street SE, Minneapolis, MN 55455, USA

jlhall@umn.edu 


\begin{abstract}
The goal of this paper is to provide an updated review for scientists and clinicians on the major areas in cardiovascular medicine published in the Journal. Leading topics in regenerative and personalized medicine are presented along with a critical overview of the field. New standards in large preclinical animal models of pulmonary hypertension and left bundle branch block are highlighted. Finally, clinical care in the area of atherosclerosis, the aortic valve, platelet biology, and myocarditis is discussed as well as autonomic modulation therapies
\end{abstract}

\title{
Regenerative Medicine
}

Following myocardial infarction, the heart loses millions of cardiomyocytes. Because the heart has a limited regenerative capacity, the lost cells are not replaced by all new myocytes but with scar, composed of extracellular matrix. Although the scar prevents cardiac rupture and is initially beneficial, the high pressure in the left ventricle causes the infarct to expand progressively, remodeling the heart and leading to heart failure [1]. In the last few years, different approaches have been developed to regenerate the injured myocardium, including administration of bone marrow stem/progenitor cells, adipose stem cells, induced pluripotent stem cell-derived cardiomyocytes sometimes combined with immunosuppressants, fibroblasts reprogrammed into cardiomyocytes, and noncoding RNAs [2-7]. Interestingly, an endogenous cell population with cardiomyocyte progenitor properties (cardiac progenitor cells, CPCs) has been recently described in the heart [8]. Although CPCs lack sufficient potential to regenerate the damaged myocardium on their own, administration of certain growth factors during the acute phase in the response to infarction can activate these cells, improving their cardiogenic potential [9]. Last year, Koudstaal and colleagues showed that this same approach is successful in a preclinical pig model of chronic myocardial infarction in which adverse cardiac remodeling is already taking place [10]. This group provides new evidence that injection of insulin-like growth factor-1 (IGF-1) and hepatocyte growth factor (HGF) as late as 4 weeks post-infarction improved cardiac contractility, especially when combined with UPy hydrogel. Administration of these factors increased the number of CPCs in the infarct region and resulted in improved angiogenesis, reduced cardiomyocyte hypertrophy, and reduced fibrosis. Furthermore, IGF-1 and HGF increased the cardiomyogenic potential of CPCs and the number of cardiomyocytes positive for Ki-67 [10]. Together, these results highlight the potential of therapeutic approaches based on the combination of growth factors and biomaterials to promote an integrative regenerative response that includes myocardial regeneration, improved angiogenesis, and reduced cardiac remodeling after myocardial infarction. These findings are especially relevant in a chronic ischemic setting like the one tested here [10].

\section{Personalized Medicine (Genomics and Electronic Health Records)}

\section{Technology and Validation}


The development of next generation sequencing technologies is rapidly advancing the discovery of gene variants associated with cardiovascular disease [11]. This has been particularly relevant for the identification of variants underlying cardiac arrhythmias [12]. However, the cost associated with the analysis of a large number of samples is still a disadvantage. Pooling samples together has emerged as an alternative to individual sequencing to reduce the overall cost. However, this approach has the main disadvantage of diluting the mutation that one patient may have wild type alleles from all other patients, making it undetectable by DNA sequencing. Interestingly, in 2014, Juan Gómez and colleagues developed a protocol that allows sensitive identification of gene variants from pooled samples [13]. The authors focused on the following DNAvariants in genes associated with long QTsyndrome or Brugada syndrome: SCN5A, KCNH2, KCNQ1, KCNE1, and KCNE2. They sequenced the exon-coding sequence of these genes in 20 patients, each of whom was heterozygous for a different variant. Variants had already been determined in these patients by Sanger sequencing. The authors were able to detect up to 16 out of the 20 known variants, with four nondetected variants being present in PCR amplicons that were covered by no reads and mapped to DNA regions with high GC content. This new protocol opens a new avenue for rapid screening of known DNA variants in large patient cohorts without the need for barcoding and with a considerable reduction in cost.

Coronary artery disease remains the leading cause of morbidity and mortality developed in developing countries. The early identification of coronary atherosclerosis may contribute to better stratification and preventive optimization of individuals at risk. Early detection and risk prediction typically relies on the traditional risk profiling or image-based early detection. Daniels et al. report on the value of a gene expression score (GES) in predicting obstructive coronary artery disease [14]. The utility of RNA (gene expression) as biomarkers used by clinicians to predict the likelihood of a clinical event in patients with coronary artery disease or clinical events in transplant patients or rejection in transplant patients has been relatively slow to replace standard imaging, stress testing, or biopsies [15]. The field of RNA biomarkers has lacked longterm studies on biological variation in stored samples on gene expression, and the effects of cardiovascular medication on gene expression and the effects of ethnicity on gene expression. These issues were all addressed in a large cohort of 1500 subjects in an expansion of the PREDICT (Personalized Risk Evaluation and Diagnosis in the Coronary Tree) cohort [14]. The major findings were that expansion to 1500 individuals replicated the previous data, the relatively small nonwhite population $(n=138)$ showed similar performance on the test as the whites, the stability of the blood samples over 5 years was good in 501 samples tested (i.e., no significant change in test performance between original set and most recent data), and finally, in the same 501 subjects, a small change in gene expression score was noted when a new blood sample was taken 5 years post and compared to the original sample [14]. Overall, this is important methodological data for the field moving forward.

\section{Lipids}

Different fat components absorbed in the intestine are transported in the blood by small particles that are composed of high, low and very low-density lipoproteins (HDL, LDL, VLDL), and apolipoproteins B and E (APOB, APOE). APOE and APOB are ligands for the LDL and VLDL receptors and are involved in 
cholesterol, vitamin, and lipoprotein transport and clearance. Lack of APOE results in accumulation of cholesterol and triglycerides in the blood, and APOE knockout mice fed with a high fat diet have been extensively used as a model of atherosclerosis in basic and preclinical research [16]. APOE is a polymorphic gene and each of its three forms $(\varepsilon 1, \varepsilon 2, \varepsilon 3)$ encodes an APOE isoform(APOE2, APOE3, APOE4) with varying affinity for LDL and VLDL receptors. Each individual can have up to two different isoforms, one for each of the two APOE alleles. Patients homozygous for $\varepsilon 3$ or $\varepsilon 4$ have increased LDL levels and are at a higher risk of developing coronary heart disease. A recent controversy has arisen with regard to the response of $\varepsilon 4 / \varepsilon 4$ carriers to omega-3 fatty acids and its potential benefits, with one report suggesting a proatherogenic effect of omega- 3 acids in these patients and another one reporting an increase in LDL-cholesterol (LDL-C), compared to $\varepsilon 3$ homozygotes. In 2014,William S. Harris and colleagues carried out a study with 136,701 patients to confirm or refute this hypothesis [17]. They found no adverse interaction between the omega-3 index (percentage of eicosapentaenoic acid and docosahexaenoic acid over total fatty acids in blood) and the APOE genotype for LDL-C, APOB, and LDL particle number. Importantly, the distribution of APOE genotypes in the studied cohort matched that of the general population, indicating that the observations can be extended to the general population. The results obtained in this study are key to understanding the effects of omega-3 fatty acids on the concentration of lipoproteins and cholesterol in the blood. They confirm a favorable relationship between the omega-3 index and cardiovascular risk and put an end to the controversy of the negative effect of omega-3 fatty acids on patients with an APOE4 homozygous genotype.

\section{Electronic Health Records}

The emerging importance of electronic health records (EHRs) in translational cardiovascular research generally [18] and more specifically in genomics [19] was clearly highlighted in two excellent reviews in the Journal in 2014. EHRs are playing an important role in clinical care but are now more fully recognized for their added value in translational by offering better access to big data. Among many issues discussed is the importance of adopting unified systems of recording information thereby allowing better integration of data—and this can present significant challenges where the data in question may range from structured, discrete datasets through to MRI imaging and even video recording. Key to the success of this overall approach is the adoption of common coding terminology. Current efforts toward an integrated EHR approach have also pointed the way forward as, for example, with the electronic and Medical Records and Genomics (eMERGE) consortium of US centers which has developed publically available EHR-based phenotype algorithms, the Electronic Healthcare Record for Clinical Research (EHR4CR) project which is highlighted for having produced a technical infrastructure to assist with integrating disparate EHRs, and the UK-based CALIBER project derived from EHRs and disease registries. It will be of interest to see how these issues play outmoving forward and how contrasting healthcare systems may offer complimentary advantages and disadvantages in terms of data collection. The effective capture of unstructured information and the use of data mining tools such as IBM Watson Analytics and SAS Context Categorization tools, which make use of natural language processing and machine learning techniques to drive hypothesis generation, are garnering the majority of attention in this field. Progress has been made in utilizing the EHRs for research and personalized medicine, yet much work remains. 


\section{Aortic Valve}

The Journal published a detailed review of molecular and mechanical interactions in the aortic valve and aorta by Krishnamurthy et al. [20]. Over the past two decades, extensive genetic investigation by several groups around the world led to the discovery of mutations in genes encoding components of the aortic extracellular matrix, the smooth muscle sarcomere, and factors involving TGF-beta and notch signaling that lead to familial aortic aneurysms. [21, 22] as the authors of this review point out, successful application of novel therapeutics for aortic aneurysm requires understanding not only of the genetic basis but also the biomechanical processes influencing aortic development and homeostasis. Their review includes the complex interplay among valve interstitial cells, valve endothelial cells, extracellular components of the aortic wall, and proteoglycans and glycosaminoglycans, all of which may influence aortic development and disease [20, 23, 24].

There is considerable debate regarding the role of abnormal hemodynamic stress imparted by bicuspid aortic valves, with or without stenosis, on the development of thoracic aortic aneurysms [25]. The influence of biomechanical stress affects the aortic valve and the aortic wall differently, as the authors acknowledge in this review. They also describe the variability of hemodynamic stress throughout the aorta. While the traditional teaching of bicuspid aortic valve-associated turbulence causing aortic aneurysm cannot sufficiently explain aortic aneurysm in this setting, the role of abnormal hemodynamic flow and variation in shear stress remains under-studied in aortic disease pathogenesis $[26,27]$. Other notable features of this review include a comprehensive summary of murine models of isolated or overlapping phenotypes with aortic valve disease and aortopathy, computational modeling of mechanobiology affecting the aortic valve and aorta, as well as the evolution of aortic prostheses and surgeries [20].

\section{Atherosclerosis}

Atherosclerosis is a systemic disease with a long asymptomatic phase where atherosclerotic plaques are generated in all vascular territories. Only when a cardiovascular complication suddenly occurs (such as myocardial infarction, and stroke) the disease is recognized. Treatment of the disease after symptoms appear represents a burden to healthcare systems and to individuals. An excellent and comprehensive review on detection strategies for subclinical atherosclerosis and assessment of progression and regression shed new light on a controversial area [28]. Fernández-Friera et al. include discussions of the current guidelines as well as global cost-effectiveness [28]. Coronary artery calcium scoring rather than carotid intima-media thickness is emerging as the most useful clinical approach for improving risk assessment among asymptomatic subjects with intermediate risk. Further development of CT-based imaging with functional evaluation using either SPECT or algorithm-based assessment of fractional flow reserve may help further advance its clinical use, thanks to the comprehensive noninvasive assessment of the obstructive coronary artery disease. Molecular imaging technology holds the experimental promise for plaque detection and characterization but is not ready for the routine clinical use. The major conclusions reached were that atherosclerotic plaques detection by multi- 
vascular ultrasound, coronary calcium quantification by computed tomography, and metabolic assessment of existing plaques by hybrid positron emission tomography/magnetic resonance imaging (PET/MR) will become part of the diagnostic package for assessing risk. Identification, quantification, and evaluation of metabolic status of atherosclerosis could help the design of preventive strategies if able to tackle these global epidemics. At the current time, no consensus has been reached on the usefulness of imaging for subclinical atherosclerosis. However, the field has determined that carotid IMT is no longer recommended for routine clinical assessment, and that coronary artery calcium is a useful diagnostic approach for those at intermediate risk [29]. The ongoing Bioimage [30] and Progression of Early Subclinical Atherosclerosis (PESA) [31] studies among others will tell whether this prediction holds true.

\section{Characterization of New Preclinical Models}

Pulmonary hypertension leads to high morbidity and mortality throughout the world [32]. Postcapillary pulmonary hypertension is the most frequent form of pulmonary hypertension [32]. Large animal models of postcapillary pulmonary hypertension that fully recapitulate the disease have been lacking. Pereda and colleagues describe a porcine model of postcapillary pulmonary hypertension induced by nonrestrictive banding of both inferior pulmonary veins [33]. Characterization with right heart catheterization and magnetic resonance showed all banded animals developed pulmonary hypertension, decreased RVejection fraction, and increased RV end-systolic volume [33]. Histopathology showed increased lung weight and fibrosis. Pulmonary arteries exhibited increased intimal and medial thickness with increased fibrosis [33]. The development of this new model represents a giant step forward for the field. A clear example of the utility of this highly translationalmodel is the demonstration thatmagnetic resonance imaging can accurately quantify changes in pulmonary vascular resistances without the need of serial invasive procedures [34]. In addition, by using this same model, it has been recently demonstrated that magnetic resonance imaging T1mapping can identify RV early dysfunction in subjects with pulmonary hypertension [35], opening the door for early identification of failing RV in the context of pulmonary hypertension. Large animal models of left bundle branch block to test cardiac resynchronization therapies or other therapies to treat left bundle branch block have been rare. Rigol et al. described the first closed chest porcine model in the Journal [29]. The porcine model uses localized endocardial radiofrequency ablation along with high rate pacing to avoid ventricular fibrillation. Left bundle branch block induction was confirmed by widening of the QRS wave, along with additional specific alterations in ECG pattern concordant with left bundle branch block including prolongation of activation time [29].

\section{Myocarditis and Heart Failure}

Five papers in the Special Issue on Myocarditis and Heart Failure in the Journal evaluated innate and adaptive immunity during experimental viral and bacterial inflammatory heart disease. Coxsackievirus B3 (CVB3) infection in mice is a wellestablished model for viral myocarditis and dilated cardiomyopathy sharing many characteristics with clinical myocarditis and dilated cardiomyopathy including the following: (1) a male bias to the disease, (2) evidence for autoimmunity to cardiac antigens, and (3) viral persistence in the heart 
resulting in chronic myocarditis and dilated cardiomyopathy (whereas viral clearance during the acute phase leads to disease resolution) [36]. CVB3 infection activates TLR3 which upregulates tissue factor expression and a hypercoagulative state [37]. Ventricular thrombi occur in both clinical and experimental myocarditis. Thrombin activates protease-activated receptor-1 (PAR-1), which promotes type 1 interferon and chemokine responses linking the coagulation and inflammation systems. Matrix metalloproteinases (MMPs) and the tissue inhibitors of matrix metalloproteinases (TIMPs) have crucial roles in myocarditis and dilated cardiomyopathy [38]. Specific MMPs and TIMPs are induced by CVB3 infection. MMP1 and MMP13 can activate PAR-1. Other MMPs promote leukocyte diapedesis. Apoptosis of cardiomyocytes is implicated in cardiac injury during ischemia and reperfusion injury. Autophagy, a cellular process allowing recycling of damaged organelles and cytosolic components, protects against apoptosis. Estrogens prevent apoptosis not only through increased expression of antiapoptotic molecules such as BCL2 family members but also through sex bias induction of autophagy [39]. Viruses use autophagosomes as platforms for replication, but autophagy also cross-presents endogenous antigens on major histocompatibility complex class II (MHCII) molecules. This pathway may be crucial in induction of autoimmunity, which is a major pathogenic factor in cardiac damage. Group A streptococcus, the cause of rheumatic heart disease [40], andCVB3 [36] both induce CD4+ Tcell responses which cross-reactively recognize microbial and heart antigens and can adoptively transfer myocarditis to naive recipients.

\section{Autonomic Modulation Therapies}

Heart failure is often characterized by changes in the autonomic nervous system, manifesting as an excess of sympathetic activity and a withdrawal of parasympathetic activity. This imbalance has been targeted traditionally with betaadrenergic blockade, renin-angiotensin-aldosterone system inhibitors, and exercise training. Device therapies, which electrically modulate the autonomic system, have also been proposed and were the focus of a series published in the Journal [41]. This series reviewed the physiological foundations for the therapies and highlighted the hurdles to translation into humans.

Baroreflex activation therapy (BAT) targetsmechanosensitive sensory nerve fibers originating from the walls of the carotid sinuses. Edoardo Gronda et al. described the consequences of baroreflex dysfunction in heart failure and presented the scientific rational, preclinical evidence, and open-label clinical trial data that led to the first randomized trial investigating BAT in heart failure patients with reduced ejection fraction [42]. The HOPE4HF study (NCT01471860, NCT01720160) enrolled 146 patients and randomized them to BAT or guidelinedirected medical therapy [43]. BAT had a favorable safety and tolerability profile and when compared to the control group, BAT demonstrated significant improvements in NYHA classification, quality of life, and 6-min hall walk distance. This body of translational research sets the stage for an event-based trial.

The first clinical studies of spinal cord stimulation (SCS) in class III systolic heart failure patients have produced mixed results. Hung-Fat Tse and colleagues enrolled 22 patients in the open-label multicenter SCS HEART trail (NCT01362725) and showed improvement over 6 months in a composite score of 6 efficacy 
parameters [44]. In contrast, it was reported at the 2014 American Heart Scientific Sessions that the single blind, randomized, controlled DEFEAT-HF trial which enrolled 81 patients (NCT01112579) failed to meet its primary and secondary efficacy endpoints at 6 months [45]. One possible explanation for the discrepant findings is that the stimulation location and intensity were not identical (i.e., continuous dual site stimulation at T1-T3 vs. intermittent single electrode stimulation at T2-T4, respectively). Although extrapolation should be done with caution, the results published by Lopshire and Zipes did demonstrate that the benefits of SCS, in an experimental heart failure model, are dependent on electrode location and stimulation intensity [46].

Stimulation parameters may also be critical for the translation of vagal nerve stimulation (VNS) to heart failure patients. De Ferrari reviewed the preclinical and clinical evidence for VNS therapy and raised the dose issue, highlighting the complexity of many parameter combinations and calling for the evaluation of dose-response curves [47]. Incomplete understanding of this dose issue may have contributed to recent translational difficulties. Although significant improvements from baseline were found in left ventricular volume and ejection fraction in the open-label ANTHEM-HF clinical trial (NCT01823887), the randomized NECTAR-HF trial (NCT01385176) failed to demonstrate a difference, between groups, in remodeling [48, 49]. These results may be attributable to trial design, but might also reflect a difference in the dose delivered. ANTHEM-HF achieved a dose of $2 \mathrm{~mA}$ using $10 \mathrm{~Hz}$, while NECTAR-HF delivered $1.2 \mathrm{~mA}$ at $20 \mathrm{~Hz}$. Additional research is needed to identify appropriate doseresponse markers and optimizeVNS therapy delivery for heart failure patients.

\section{Invasive Cardiovascular Therapies}

The last few years have significantly pushed the frontier of invasive cardiovascular therapies forward. Treatment of valvular heart disease is becoming less invasive, particularly for higher risk patient subsets. Percutaneous approaches to previously untreatable coronary and peripheral vascular disease are now commonplace. Device therapies for stroke prevention in atrial fibrillation are reducing the need for anticoagulation in high-risk patients. And finally, novel stent platforms are emerging that may lead to improved percutaneous coronary intervention outcomes. Minimally Invasive Valve Therapies Multidisciplinary heart teams, including cardiologists, cardiac surgeons, anesthesiologists, and radiologists, have emerged as the state of the art in caring for patients with valvular heart disease and have resulted in optimization of patient care plans and outcomes. Landmark clinical trials such as the PARTNER and EVEREST trials have established the use of percutaneous approaches for the treatment of aortic stenosis and mitral regurgitation in patient populations with perceived high surgical risk. Concerns regarding increased stroke incidence compared to surgery, heart block requiring pacemaker, and paravalvular leaks have limited widespread adoption of percutaneous aortic valve therapies in lower risk populations. Smaller delivery systems and improved valve design strive to improve procedural safety and long-term efficacy [50]. Surgical valve therapies are becoming less invasive. Balloon expandable and selfexpanding aortic valves are being used surgically to avoid need for suture, thus, decreasing operating and cardiopulmonary bypass times. Development of minimally invasive approaches to surgical valve repair and replacement, such as the mini sternotomy and right sided thoracotomy approaches, has resulted in sternal sparing, a quicker return to activity and greater patient satisfaction. Pope et al. nicely describe in detail the 
performance and benefits of these cutting edge approaches to both aortic valve replacement and mitral valve repair [51].

\section{Percutaneous Treatment of Coronary and Peripheral Vascular Disease}

Chronic total occlusions (CTOs) are often referred to as the last frontier of percutaneous coronary intervention. With more effective medical therapies and more aggressive revascularization strategies, patients with coronary artery disease (CAD) are living longer. Due to this, CTOs are more common and present in 18.4 to $52 \%$ of patients with CAD undergoing angiography. Advances in technique and equipment have resulted in successful antegrade and retrograde approaches to opening CTOs, resulting in anginal symptom improvement, increased exercise tolerance, improvement in left ventricular function, decreased need for more invasive coronary artery bypass grafting, and decreased mortality. Emmanouil Brilakis, one of the pioneers in this area, presents an excellent review of the techniques used in this constantly growing field [52]. Percutaneous approaches to critical limb ischemia have also seen great growth. Drug-eluting stent and balloon platforms have increased the success of intervention and decreased amputation rates. Endothelial progenitor cells and bone marrow mononuclear cells have shown promise in critical limb ischemia in small trials but larger trials are still needed to establish this therapy as effective [53].

\section{Device Therapies for Stroke Prevention in Atrial Fibrillation}

With the aging population, atrial fibrillation (AF) is the most commonly occurring cardiac arrhythmia requiring medical attention. Strategies for stroke prevention in AF have mostly centered on anticoagulation therapies. Newer anticoagulants such as dabigatran, apixaban, and rivaroxaban have proven to be at least equivalent to warfarin and potentially provide more reliable anticoagulation; however, the risk for bleeding complications still remains. Device-based alternatives for stroke prevention are, thus, appealing in patients at high risk for bleeding. Several devices are now in use including the Amplatzer left atrial appendage occlude (St. Jude Medical), the Watchman closure device (Aritech, Inc.), and the Lariat device (Sentre HEART). Hussein et al. present a comprehensive review of each device, focusing on patient selection and device delivery [54].

\section{Novel Stent Platforms}

Coronary stents have evolved significantly over time with changes in polymer, strut thickness, type of drug delivered, and the pharmacokinetics of drug delivery with the goal of reducing stent thrombosis and restenosis. Current second generation drug-eluting stents, while performing much better in both regards, have not fully eliminated in-stent restenosis and are plagued by late stent thrombosis when re-endothelialization of the metal scaffold is not complete. Drug-eluting bioresorbable scaffolds have the potential to address both of these issues. Porcine models have been used to develop a first generation magnesium BVS that is now under investigation in the large multicenter DREAMS-2 trial. Magnesium scaffolds may demonstrate a balance between suppression of vascular smooth muscle cell proliferation and enhancement of endothelial cell proliferation resulting in less neointimal growth and return of a normal endothelium. Interest in polymeric, as opposed to metal scaffolds, is 
also attractive as there may be fewer corrosion products deposited in the artery wall. However, increased strut thickness may impair deliverability and delayed resorption may impair their potential benefits on vascular biology. The ABSORB II and RESTORE II trials are now underway to test this platform type in a large clinical trial. To date, bioresorbable scaffolds have been studied only in elective PCI and their ability to reduce the need for prolonged dual antiplatelet therapy is unclear [55].

\section{Antiplatelet Therapy Optimization: from Inflammation to Acute Coronary Syndrome}

The Journal published a special issue dedicated to the role of platelets from the onset of vascular atherosclerosis to acute coronary syndromes (ACS) [56-60]. The heterogeneity in response to current antiplatelet regimens with related clinical implications has been described in the following clinical settings [61-64]: (a) an impaired response to clopidogrel has been observed under conditions mimicking the hypothermic state of the comatose patients after ACS undergoing percutaneous coronary interventions (PCI), [62] (b) difficult therapeutic management with related increased bleeding risk in patients under chronic anticoagulation treated with PCI [60], (c) challenges of bridging antiplatelet therapy in patients requiring cardiac and noncardiac surgery [64], and (d) the gender differences in antiplatelet treatments and responses [65]. Future areas of investigations have been proposed in novel antiplatelet agents able to potently and safely inhibit platelet reactivity [66, 67]. Ridogrel and picotamide are novel inhibitors of the thromboxane (Tx) A2 pathway that promise to overcome the limitations of aspirin (the most widely used inhibitor of TxA2 synthesis) in blocking the isoprostanes. These novel inhibitors might prove particularly useful in selected patients like those with diabetes. Finally, a novel pharmacomechanical strategy based on the use of transradial access site and bivalirudin infusion has been proposed at the time of PCI for ACS patients in the MATRIX trial [68]. The MATRIX trial showed that radial as compared with femoral access reduced net adverse clinical events, through a reduction in major bleeding and all-cause mortality [69], while no significant differences were observed with bivalirudin as compared with unfractionated heparin [70].

\section{References}

1. Lopez-Olaneta, M. M., Villalba, M., Gomez-Salinero, J. M., Jimenez-Borreguero, L. J., Breckenridge, R., Ortiz-Sanchez, P., Garcia-Pavia, P., Ibanez, B., \& Lara-Pezzi, E. (2014). Induction of the calcineurin variant CnAbetal after myocardial infarction reduces post-infarction ventricular remodelling by promoting infarct vascularization. Cardiovascular Research, 102, 396-406.

2. Hudson, J. E., \& Porrello, E. R. (2013). The non-coding road towards cardiac regeneration. Journal of Cardiovascular Translational Research, 6, 909-923.

3. Bernal, J. A. (2013). RNA-based tools for nuclear reprogramming and lineage-conversion: towards clinical applications. Journal of Cardiovascular Translational Research, 6, 956-968. 
4. Inagawa, K., \& Ieda, M. (2013). Direct reprogramming of mouse fibroblasts into cardiac myocytes. Journal of Cardiovascular Translational Research, 6, 37-45.

5. Jansen Of Lorkeers, S. J., Hart, E., Tang, X. L., Chamuleau, M. E., Doevendans, P. A., Bolli, R., \& Chamuleau, S. A. (2014).

Cyclosporin in cell therapy for cardiac regeneration. Journal of Cardiovascular Translational Research, 7, 475-482.

6. Chen, L., Qin, F., Ge, M., Shu, Q., \& Xu, J. (2014). Application of adipose-derived stem cells in heart disease. Journal of Cardiovascular Translational Research, 7, 651-663.

7. Fuh, E., \& Brinton, T. J. (2009). Bone marrow stem cells for the treatment of ischemic heart disease: a clinical trial review. Journal of Cardiovascular Translational Research, 2, 202-218.

8. Ellison, G. M., Nadal-Ginard, B., \& Torella, D. (2012). Optimizing cardiac repair and regeneration through activation of the endogenous cardiac stem cell compartment. Journal of Cardiovascular Translational Research, 5, 667-677.

9. Ellison, G. M., Torella, D., Dellegrottaglie, S., Perez-Martinez, C., Perez de Prado, A., Vicinanza, C., Purushothaman, S., Galuppo, V., Iaconetti, C., Waring, C. D., Smith, A., Torella, M., Cuellas Ramon, C., Gonzalo-Orden, J. M., Agosti, V., Indolfi, C., Galinanes, M., Fernandez-Vazquez, F., \& Nadal-Ginard, B. (2011). Endogenous cardiac stem cell activation by insulin-like growth factor-1/hepatocyte growth factor intracoronary injection fosters survival and regeneration of the infarcted pig heart. Journal of the American College of Cardiology, 58, 977-986.

10. Koudstaal, S., Bastings, M. M., Feyen, D. A., Waring, C. D., van Slochteren, F. J., Dankers, P. Y., Torella, D., Sluijter, J. P., NadalGinard, B., Doevendans, P. A., Ellison, G.M., \& Chamuleau, S. A. (2014). Sustained delivery of insulin-like growth factor-1/hepatocyte growth factor stimulates endogenous cardiac repair in the chronic infarcted pig heart. Journal of Cardiovascular Translational Research, 7, 232-241.

11. Barbato, E., Lara-Pezzi, E., Stolen, C., Taylor, A., Barton, P. J., Bartunek, J., Iaizzo, P., Judge, D. P., Kirshenbaum, L., Blaxall, B. C., Terzic, A.,\&Hall, J. L. (2014). Advances in induced pluripotent stem cells, genomics, biomarkers, and antiplatelet therapy highlights of the year in JCTR 2013. Journal of Cardiovascular Translational Research, 7, 518-525.

12. Ware, J. S., John, S., Roberts, A. M., Buchan, R., Gong, S., Peters, N. S., Robinson, D. O., Lucassen, A., Behr, E. R., \& Cook, S. A.

(2013). Next generation diagnostics in inherited arrhythmia syndromes: a comparison of two approaches. Journal of

Cardiovascular Translational Research, 6, 94-103.

13. Gomez, J., Reguero, J. R.,Moris, C., Alvarez, V., \& Coto, E. (2014). Non optical semi-conductor next generation sequencing of the main cardiac QT-interval duration genes in pooled DNA samples. Journal of 
Cardiovascular Translational Research, 7, 133-137.

14. Daniels, S. E., Beineke, P., Rhees, B., McPherson, J. A., Kraus,W. E., Thomas, G. S., \& Rosenberg, S. (2014). Biological and analytical stability of a peripheral blood gene expression score for obstructive coronary artery disease in the PREDICT and COMPASS studies. Journal of Cardiovascular Translational Research, 7, 615-622. 15. Fox, C. S., Hall, J. L., Arnett, D. K.,Ashley, E. A., Delles, C., Engler, M. B., Freeman, M. W., Johnson, J. A., Lanfear, D. E., Liggett, S. B., Lusis, A. J., Loscalzo, J.,MacRae, C. A.,Musunuru, K., Newby, L. K., O'Donnell, C. J., Rich, S. S., Terzic, A., American Heart Association Council on Functional G, Translational Biology CoC, Stroke Nursing CoCCCoQoC, \& Outcomes R, Council on E and Prevention. (2015). Future translational applications from the contemporary genomics era: a scientific statement from the American Heart Association.

Circulation, 131, 1715-1736.

16. Briley-Saebo, K., Yeang, C., Witztum, J. L., \& Tsimikas, S. (2014). Imaging of oxidation-specific epitopes with targeted nanoparticles to detect high-risk atherosclerotic lesions: progress and future directions. Journal of Cardiovascular Translational Research, 7, 719-736. 17. Harris,W. S., Pottala, J. V., Thiselton, D. L., Varvel, S. A., Baedke, A. M., Dayspring, T. D.,Warnick, G. R.,\&McConnell, J. P. (2014). Does APOE genotype modify the relations between serumlipid and erythrocyte omega-3 fatty acid levels? Journal of Cardiovascular Translational Research, 7, 526-532.

18. Rasmussen, L. V. (2014). The electronic health record for translational research. Journal of Cardiovascular Translational Research,

7, 607-614.

19. Krishnamoorthy, P., Gupta, D., Chatterjee, S., Huston, J., \& Ryan, J. J. (2014). A review of the role of electronic health record in genomic research. Journal of Cardiovascular Translational Research,

7, 692-700.

20. Krishnamurthy, V. K., Godby, R. C., Liu, G. R., Smith, J. M., Hiratzka, L. F., Narmoneva, D. A., \& Hinton, R. B. (2014).

Review ofmolecular and mechanical interactions in the aortic valve and aorta: implications for the shared pathogenesis of aortic valve disease and aortopathy. Journal of Cardiovascular Translational Research, 7, 823-846.

21. Guo, D. C., Papke, C. L., He, R., \& Milewicz, D. M. (2006).

Pathogenesis of thoracic and abdominal aortic aneurysms. Annals of the New York Academy of Sciences, 1085, 339-352.

22. Lindsay,M. E., \& Dietz, H. C. (2011). Lessons on the pathogenesis of aneurysm from heritable conditions. Nature, 473, 308-316.

23. Adhikari, N., Carlson, M., Lerman, B., \& Hall, J. L. (2011).

Changes in expression of proteoglycan core proteins and heparan sulfate enzymes in the developing and adult murine aorta. Journal of Cardiovascular Translational Research, 4, 313-320.

24. Bischoff, J., \& Aikawa, E. (2011). Progenitor cells confer plasticity 
to cardiac valve endothelium. Journal of Cardiovascular

Translational Research, 4, 710-719.

25. Michelena, H. I., Prakash, S. K., Della Corte, A., Bissell, M. M., Anavekar, N., Mathieu, P., Bosse, Y., Limongelli, G., Bossone, E., Benson, D. W., Lancellotti, P., Isselbacher, E. M., Enriquez-Sarano, M., Sundt, T. M., 3rd, Pibarot, P., Evangelista, A., Milewicz, D. M., Body, S. C., \& Investigators, B. A. (2014). Bicuspid aortic valve: identifying knowledge gaps and rising to the challenge from the International Bicuspid Aortic Valve Consortium (BAVCon).

Circulation, 129, 2691-2704.

26. Kent, K. C., Crenshaw, M. L., Goh, D. L., \& Dietz, H. C. (2013). Genotype-phenotype correlation in patients with bicuspid aortic valve and aneurysm. The Journal of Thoracic and

Cardiovascular Surgery, 146, 158-165. e1.

27. Loscalzo, M. L., Goh, D. L., Loeys, B., Kent, K. C., Spevak, P. J.,\&

Dietz, H. C. (2007). Familial thoracic aortic dilation and

bicommissural aortic valve: a prospective analysis of natural history and inheritance. American Journal of Medical Genetics Part A,

143A, 1960-1967.

28. Fernandez-Friera, L., Ibanez, B., \& Fuster, V. (2014). Imaging subclinical atherosclerosis: is it ready for prime time? A review.

Journal of Cardiovascular Translational Research, 7, 623-634.

472 J. of Cardiovasc. Trans. Res. (2015) 8:466-474

29. Rigol,M., Solanes, N., Fernandez-Armenta, J., Silva, E., Doltra, A.,

Duchateau, N., Barcelo, A., Gabrielli, L., Bijnens, B., Berruezo, A.,

Brugada, J., \& Sitges, M. (2013). Development of a swinemodel of left bundle branch block for experimental studies of cardiac resynchronization therapy. Journal of Cardiovascular Translational Research, 6, 616-622.

30. Baber, U., Mehran, R., Sartori, S., Schoos, M. M., Sillesen, H., Muntendam, P., et al. (2015). Prevalence, impact, and predictive value of detecting subclinical coronary and carotid atherosclerosis in asymptomatic adults: the BioImage study. Journal of the American College of Cardiology, 65(11), 1065-74 (2015). doi:10. 1016/j.jacc.2015.01.017.

31. Fernández-Friera, L., Peñalvo, J. L., Fernández-Ortiz, A., Ibañez, B., López-Melgar, B., Laclaustra, M., et al. (2015). Prevalence, vascular distribution, and multiterritorial extent of subclinical atherosclerosis in a middle-aged cohort: the PESA (Progression of

Early Subclinical Atherosclerosis) Study. Circulation, 131(24),

2104-13 (2015). doi:10.1161/CIRCULATIONAHA.114.014310. 32. Gheorghiade, M., Filippatos, G., De Luca, L., \& Burnett, J. (2006). Congestion in acute heart failure syndromes: an essential target of evaluation and treatment. The American Journal of Medicine, 119, S3-S10.

33. Pereda, D., Garcia-Alvarez, A., Sanchez-Quintana, D., Nuno, M., Fernandez-Friera, L., Fernandez-Jimenez, R., Garcia-Ruiz, J. M., 
Sandoval, E., Aguero, J., Castella, M., Hajjar, R. J., Fuster, V., \& Ibanez, B. (2014). Swine model of chronic postcapillary pulmonary hypertension with right ventricular remodeling: long-term characterization by cardiac catheterization, magnetic resonance, and pathology.

Journal of Cardiovascular Translational Research, 7, 494-506. 34. García-Álvarez, A., Fernández-Friera, L., García-Ruiz, J. M., Nuño-Ayala, M., Pereda, D., Fernández-Jiménez, R., et al. (2013). Noninvasive monitoring of serial changes in pulmonary vascular resistance and acute vasodilator testing using cardiac magnetic resonance. Journal of the American College of Cardiology, 62(17),

1621-31 (2013). doi:10.1016/j.jacc.2013.07.037.

35. García-Álvarez, A., García-Lunar, I., Pereda, D., Fernández-

Jimenez, R., Sánchez-González, J., Mirelis, J. G., et al. (2015).

Association of myocardial T1-mapping CMR with hemodynamics and RV performance in pulmonary hypertension. JACC.

Cardiovascular Imaging, 8(1), 76-82 (2015). doi:10.1016/j.jcmg. 2014.08.012.

36. Massilamany, C., Huber, S. A., Cunningham, M. W., \& Reddy, J. (2014). Relevance of molecular mimicry in the mediation of infectious myocarditis. Journal of Cardiovascular Translational

Research, 7, 165-171.

37. Antoniak, S., \& Mackman, N. (2014). Coagulation, proteaseactivated receptors, and viral myocarditis. Journal of Cardiovascular Translational Research, 7, 203-211.

38. Hendry, R. G., Bilawchuk, L. M., \& Marchant, D. J. (2014).

Targeting matrix metalloproteinase activity and expression for the treatment of viral myocarditis. Journal of Cardiovascular Translational Research, 7, 212-225.

39. Koenig, A., Sateriale, A., Budd, R. C., Huber, S. A., \& Buskiewicz, I. A. (2014). The role of sex differences in autophagy in the heart during coxsackievirus B3-induced myocarditis. Journal of Cardiovascular Translational Research, 7, 182-191.

40. Kirvan, C. A., Galvin, J. E., Hilt, S., Kosanke, S., \& Cunningham, M. W. (2014). Identification of streptococcal m-protein cardiopathogenic epitopes in experimental autoimmune valvulitis. Journal of Cardiovascular Translational Research, 7, 172-181.

41. Abraham, W. T., \& De Ferrari, G. M. (2014). Novel nonpharmacological approaches to heart failure. Journal of

Cardiovascular Translational Research, 7, 263-265.

42. Gronda, E., Lovett, E. G., Tarascio, M., Georgakopoulos, D., Grassi, G., \& Vanoli, E. (2014). The baroreceptor as a therapeutic target for heart failure. Journal of Cardiovascular Translational Research, 7, 301-309.

43. Abraham,W. T., Zile, M. R.,Weaver, F. A., Butter, C., Ducharme, A., Halbach,M., Klug, D., Lovett, E. G.,Muller-Ehmsen, J., Schafer, J. E., Senni, M., Swarup, V.,Wachter, R., \& Little,W. C. (2015). Baroreflex activation therapy for the treatment of heart failure with a reduced 
ejection fraction. JACC Heart Failure, 3, 487-496.

44. Tse, H. F., Turner, S., Sanders, P., Okuyama, Y., Fujiu, K., Cheung,

C. W., Russo, M., Green, M. D., Yiu, K. H., Chen, P., Shuto, C.,

Lau, E. O., \& Siu, C. W. (2015). Thoracic spinal cord stimulation

for heart failure as a restorative treatment (SCS HEART study):

first-in-man experience. Heart Rhythm : The Official Journal of

the Heart Rhythm Society, 12, 588-595.

45. Zipes DP. (2014) Ventricular functional response to spinal cord

stimulatioin for advanced heart failure: primary results of hte randomized

DEFEAT-HF trial. 2014.

46. Lopshire, J. C., \& Zipes, D. P. (2014). Spinal cord stimulation for

heart failure: preclinical studies to determine optimal stimulation

parameters for clinical efficacy. Journal of Cardiovascular

Translational Research, 7, 321-329.

47. De Ferrari, G. M. (2014). Vagal stimulation in heart failure. Journal of Cardiovascular Translational Research, 7, 310-320.

48. Dicarlo, L., Libbus, I., Amurthur, B., Kenknight, B. H.,\& Anand, I.

S. (2013). Autonomic regulation therapy for the improvement of left ventricular function and heart failure symptoms: theANTHEMHF study. Journal of Cardiac Failure, 19, 655-660.

49. Zannad, F., De Ferrari, G. M., Tuinenburg, A. E., Wright, D., Brugada, J., Butter, C., Klein, H., Stolen, C., Meyer, S., Stein, K. M., Ramuzat, A., Schubert, B., Daum, D., Neuzil, P., Botman, C., Castel, M. A., D'Onofrio, A., Solomon, S. D., Wold, N., \& Ruble, S. B. (2015). Chronic vagal stimulation for the treatment of low ejection fraction heart failure: results of the NEural Cardiac TherApy foR Heart Failure (NECTAR-HF) randomized controlled trial. European Heart Journal, 36, 425-433.

50. Steinberg, D. H., Castillo-Sang, M., \& Powers, E. R. (2014).

Advances in transcatheter valve therapies. Journal of

Cardiovascular Translational Research, 7, 375-386.

51. Pope, N. H., \&Ailawadi, G. (2014). Minimally invasive valve surgery. Journal of Cardiovascular Translational Research, 7, 387-394.

52. Brilakis, E. S., Karmpaliotis, D.,Vo, M. N., Garcia, S., Michalis, L., Alaswad, K., Doshi, P., Lombardi, W. L., \& Banerjee, S. (2014). Advances in the management of coronary chronic total occlusions. Journal of Cardiovascular Translational Research, 7, 426-436. 53. Singh, K. P., \& Sharma, A. M. (2014). Critical limb ischemia: current approach and future directions. Journal of Cardiovascular Translational Research, 7, 437-445.

54. Hussain, S. K., Malhotra, R., \& DiMarco, J. P. (2014). Left atrial appendage devices for stroke prevention in atrial fibrillation. Journal of Cardiovascular Translational Research, 7, 458-464. 55. Lipinski, M. J., Escarcega, R. O., Lhermusier, T., \& Waksman, R. (2014). The effects of novel, bioresorbable scaffolds on coronary vascular pathophysiology. Journal of Cardiovascular Translational Research, 7, 413-425. 
56. Di Serafino, L., Sarma, J., Dierickx, K., Ntarladimas, I., Pyxaras, S. A., Delrue, L., De Bruyne, B., Wijns, W., Barbato, E., \& Bartunek, J.

(2014). Monocyte-platelets aggregates as cellular biomarker of endothelium-dependent coronary vasomotor dysfunction in patients with coronary artery disease. Journal of Cardiovascular Translational Research, 7, 1-8.

57. Marini, M. G., Sonnino, C., Previtero, M., \& Biasucci, L. M. (2014). Targeting inflammation: impact on atherothrombosis. Journal of Cardiovascular Translational Research, 7, 9-18.

58. Schulz, S., Angiolillo, D. J., Antoniucci, D., Bernlochner, I., Hamm, C., Jaitner, J., Laugwitz, K. L., Mayer, K., von Merzljak, B., Morath, T., Neumann, F. J., Richardt, G., Ruf, J., Schomig, G., Schuhlen, H., Schunkert, H., Kastrati, A., \& Intracoronary S and J. of Cardiovasc. Trans. Res. (2015) 8:466-474 473 Antithrombotic Regimen: Rapid Early Action for Coronary Treatment 5 Trial I. (2014). Randomized comparison of ticagrelor versus prasugrel in patients with acute coronary syndrome and planned invasive strategy - design and rationale of the Intracoronary Stenting and Antithrombotic Regimen: Rapid Early Action for Coronary Treatment (ISAR-REACT) 5 trial. Journal of Cardiovascular Translational Research, 7, 91-100.

59. Thomas, M. R., \& Storey, R. F. (2014). Impact of aspirin dosing on the effects of P2Y12 inhibition in patients with acute coronary syndromes. Journal of Cardiovascular Translational Research, 7, 19-28.

60. Bennaghmouch, N., Sprenkeler, D., Qaderdan, K., \& ten Berg, J. M. (2014). Optimizing antithrombotic therapy after coronary stent implantation in patients on chronic oral anticoagulation. Journal of Cardiovascular Translational Research, 7, 64-71.

61. Cho, J. R., Desai, B., Haas, M. J., Rollini, F., Franchi, F., MunizLozano, A., Tello-Montoliu, A., Ferrante, E., Guzman, L. A., Bass, T. A., \& Angiolillo, D. J. (2014). Impact of cigarette smoking on P2Y12 receptor binding activity before and after clopidogrel therapy in patients with coronary artery disease. Journal of Cardiovascular Translational Research, 7, 47-52.

62. Ferreiro, J. L., Sanchez-Salado, J. C., Gracida, M., Marcano, A. L., Roura, G., Ariza, A., Gomez-Lara, J., Lorente, V., Romaguera, R., Homs, S., Sanchez-Elvira, G., Teruel, L., Rivera, K., Sosa, S. G., Gomez-Hospital, J. A., Angiolillo, D. J., \& Cequier, A. (2014). Impact of mild hypothermia on platelet responsiveness to aspirin and clopidogrel: an in vitro pharmacodynamic investigation. Journal of Cardiovascular Translational Research, 7, 39-46. 63. Rollini, F., Franchi, F., Cho, J. R., Degroat, C., Bhatti, M., Ferrante, E., Patel, R., Darlington, A., Tello-Montoliu, A., Desai, B., Ferreiro, J., Muniz-Lozano, A., Zenni, M. M., Guzman, L. A., Bass, T. A., \& Angiolillo, D. J. (2014). Cigarette smoking and antiplatelet effects of aspirin monotherapy versus clopidogrel monotherapy in patients with atherosclerotic disease: results of a prospective pharmacodynamic 
study. Journal of Cardiovascular Translational Research, 7, 53-63.

64. Capodanno, D.,\&Tamburino, C. (2014). Bridging antiplatelet therapy in patients requiring cardiac and non-cardiac surgery: from bench to bedside. Journal of Cardiovascular Translational

Research, 7, 82-90.

65. Marcucci, R., Cioni, G., Giusti, B., Fatini, C., Rossi, L., Pazzi, M., \& Abbate, R. (2014). Gender and anti-thrombotic therapy: from biology to clinical implications. Journal of Cardiovascular Translational Research, 7, 72-81.

66. Badr Eslam, R., Posch, F., Lang, I. M., Gremmel, T., Eichelberger, B., Ay, C., \& Panzer, S. (2014). Association of thrombin generation potential with platelet PAR-1 regulation and P-selectin expression in patients on dual antiplatelet therapy. Journal of Cardiovascular Translational Research, 7, 126-132.

67. Fontana, P., Zufferey, A., Daali, Y., \& Reny, J. L. (2014). Antiplatelet therapy: targeting the TxA2 pathway. Journal of Cardiovascular Translational Research, 7, 29-38.

68. Valgimigli, M., Calabro, P., Cortese, B., Frigoli, E., Garducci, S., Rubartelli, P., Ando, G., Santarelli, A., Galli, M., Garbo, R., Repetto, A., Ierna, S., Briguori, C.,Limbruno, U., Violini, R., Gagnor, A.,\&M Investigators. (2014). Scientific foundation and possible implications for practice of the Minimizing Adverse Haemorrhagic Events by Transradial Access Site andSystemic Implementation of AngioX (MATRIX) trial. Journal of Cardiovascular Translational Research,

7, 101-111.

69. Valgimigli, M., Gagnor, A., Calabro, P., Frigoli, E., Leonardi, S., Zaro, T., Rubartelli, P., Briguori, C., Ando, G., Repetto, A., Limbruno, U., Cortese, B., Sganzerla, P., Lupi, A., Galli, M., Colangelo, S., Ierna, S., Ausiello, A., Presbitero, P., Sardella, G., Varbella, F., Esposito, G., Santarelli, A., Tresoldi, S., Nazzaro, M., Zingarelli, A., de Cesare, N., Rigattieri, S., Tosi, P., Palmieri, C., Brugaletta, S., Rao, S. V., Heg, D., Rothenbuhler, M., Vranckx, P., Juni, P., \& M.Investigators. (2015). Radial versus femoral access in patients with acute coronary syndromes undergoing invasive management: a randomised multicentre trial. Lancet, 385, 2465-2476.

70. Valgimigli, M., Frigoli, E., Leonardi, S., Rothenbuhler,M., Gagnor, A., Calabro, P., Garducci, S., Rubartelli, P., Briguori, C., Ando, G., Repetto, A., Limbruno, U., Garbo, R., Sganzerla, P., Russo, F., Lupi, A., Cortese, B., Ausiello, A., Ierna, S., Esposito, G., Presbitero, P., Santarelli, A., Sardella, G., Varbella, F., Tresoldi, S., de Cesare, N., Rigattieri, S., Zingarelli, A., Tosi, P., Van't Hof, A., Boccuzzi, G., Omerovic, E., Sabate, M., Heg, D., Juni, P., Vranckx, P., \& M Investigators. (2015). Bivalirudin or unfractionated heparin in acute coronary syndromes. The New England Journal of Medicine, 373, 997-1009. 